\title{
EL DESPIDO POR ENFERMEDAD: ¿UN DESPIDO JUSTO O DISCRIMINATORIO?
}

\section{DISMISSAL DUE TO ILLNESS: A FAIR OR DISCRIMINA- TORY DISMISSAL?}

\author{
Ignacio Vazquez ${ }^{1}$ \\ DOI: https://doi.org/10.37767/2591-3476(2020)28 \\ Comentario a \\ STC 118/2019, de 16 de octubre de 2019 \\ Tribunal Constitucional de España
}

\author{
Disponible en \\ https://bit.ly/3I1LC96
}

\section{RESUMEN:}

Las ausencias laborales por enfermedad son consideradas, en algunos supuestos, una justa causa de despido laboral. El conflicto viene dado por el interés empresarial en combatir el absentismo laboral, por un lado, y los derechos fundamentales del trabajador, por el otro. Asimismo, recientes pronunciamientos judiciales a nivel europeo tienden a asimilar cada vez más a la enfermedad con la discapacidad, con la consiguiente nulidad de los despidos basados en este motivo por su carácter discriminatorio. La sentencia bajo análisis ofrece elementos interesantes para el debate en torno a los derechos laborales, el conflicto de derechos y la ponderación, así como la proporcionalidad de las medidas restrictivas de derechos.

\begin{abstract}
Absence from work due to illness is considered, in some cases, a just cause for dismissal. The interest in fighting absenteeism usually clashes with the fundamental rights of the workers. In addition, recent judicial pronouncements at a European level tend to assimilate illness with disability, which leads to the subsequent nullity of dismissals based on this cause for its discriminatory character. The judgment hereby analyzed offers interesting elements for the debate about labor rights, conflict of rights and weighing, as well as the proportionality of legal measures restrictive of fundamental rights.
\end{abstract}

1 Abogado (UBA); Magíster en Derecho Constitucional (CEPC - UIMP); Profesor auxiliar en la Cátedra de Derecho de la Integración (UBA). Mail: vazquezignacio32@gmail.com. Nro. de ORCID: https://orcid.org/0000-0001-7208-9145 
PALABRAS CLAVE: Despido; absentismo; enfermedad; discapacidad; proporcionalidad.

KEY WORDS: Dismissal; absenteeism; illness; disability; proportionality.

\section{Introducción}

La Sentencia del Tribunal Constitucional (STC, en adelante) 118/2019, de 16 de Octubre de 2019, resuelve la cuestión de inconstitucionalidad planteada por el Juzgado de lo Social número 26 de Barcelona en relación con el artículo 52.d de la Ley del Estatuto de los Trabajadores (LET, en adelante) por posible vulneración de los derechos a la integridad física (art. 15 CE), al trabajo (art. 35.1 CE), y a la protección de la salud (art. $43.1 \mathrm{CE}$ ), en la medida en que el precepto legal cuestionado permite al empresario extinguir la relación laboral por causa de absentismo derivado de enfermedades de corta duración del trabajador.

Los hechos que dieron lugar al planteamiento de la cuestión de constitucionalidad se relacionan con la demanda interpuesta ante el juzgado de Barcelona por una trabajadora que fue despedida de su trabajo por ausentarse por incapacidad temporal durante un período de tiempo que, bajo el art. 52.d de la LET, habilitaba al empleador a proceder al despido. ${ }^{2}$ En efecto, las ausencias al trabajo estaban demostradas, pero lo que se cuestionaba el juzgado de Barcelona era la constitucionalidad de la disposición de la LET que habilitaba los despidos en dicha circunstancia de ausencia intermitente por incapacidad temporal.

Tras un análisis de la posible vulneración de los diversos derechos puestos en escena por el juzgado de Barcelona, el Tribunal Constitucional concluye en la constitucionalidad del art. 52.d de la LET por las razones que seguidamente se examinaran, poniendo el foco en el esquema argumental que el Tribunal utiliza para plantear una supuesta colisión de derechos y la incidencia de la jurisprudencia europea en la materia. Asimismo se retomarán conceptos tradicionales como los de contenido esencial del derecho y juicio de ponderación que resultan centrales para el análisis de la sentencia, y se explicara que incidencia tiene todo ello en la determinación de la justa causa del despido laboral, algo que, como se verá, constituye el quid de la cuestión.

\section{Un tribunal dividido: el foco importa.}

Si bien la sentencia bajo análisis se inclina con claridad hacia la constitucionalidad del art. 52.d de la LET, lo cierto es que existe una disidencia nada despreciable compuesta de cuatros votos particulares sobre los que vale la pena detenerse. Resulta interesante analizar la construcción argumental tanto de los votos de mayoría como los particulares para entender cómo alcanzan soluciones tan diversas, qué rol cumple la ponderación y cuál es el grado de libertad con que un tribunal nacional como el Tribunal Constitucional puede interpretar la doctrina del Tribunal de Justicia de la Unión Europea.

$2 \mathrm{El}$ artículo 52. d de la Ley de Estatuto de los Trabajadores dispone que el contrato podrá extinguirse por ausencias justificadas que alcancen el veinte por ciento de las jornadas hábiles en dos meses consecutivos siempre que el total de faltas de asistencia en los doce meses anteriores alcance el cinco por ciento de las jornadas hábiles, o el veinticinco por ciento en cuatro meses discontinuos dentro de un periodo de doce meses. 


\section{Las razones de la mayoría.}

El Tribunal Constitucional en su voto de mayoría analiza pormenorizadamente las posibles vulneraciones de los derechos a la integridad física, al trabajo y a la salud por el art. 52 d) de la LET. Para ello, se ocupa de aclarar previamente que la disposición cuestionada responde al objetivo legítimo de proteger la productividad de la empresa y eficiencia en el trabajo que encuentra fundamento en el art. $38 \mathrm{CE}$, que garantiza la libertad de empresa y encomienda a los poderes públicos la defensa de la productividad. En esta línea, el Tribunal hace expresa referencia a la Sentencia del Tribunal de Justicia de la Unión Europea (STJUE en adelante) en el asunto Ruiz Conejero33, para resaltar que también en dicho pronunciamiento el TJUE avala que combatir el absentismo laboral es una finalidad legítima y que corresponde a los órganos jurisdiccionales verificar que la medida aplicada no va más allá de lo necesario para alcanzar ese fin legítimo, debiendo tener en cuenta para llevar a cabo esa verificación los costes directos e indirectos que han de soportar las empresas como consecuencia del absentismo laboral. (FJ 3). Es importante destacar este enfoque, porque es el tamiz por el cual el Tribunal pasa la posible vulneración de derechos, para finalmente descartarla por no existir, a su juicio, una restricción desproporcionada de los mismos en función de la legítima consecución de la finalidad de combatir el absentismo laboral.

Así, y respecto al derecho a la integridad física (art. 15 CE) el Tribunal recuerda la conexión del mismo con el derecho a la salud (art. 43.1) y extrae una regla de su propia jurisprudencia que indica que una determinada actuación empresarial en relación con las bajas por enfermedad del trabajador solo podría reputarse que afecta el ámbito protegido por el artículo 15 CE cuando existiera un riesgo relevante de que la lesión pueda llegar a producirse, lo que tendría lugar cuando se genere un peligro cierto y grave para la salud del afectado. Sin embargo, el Tribunal no aprecia que la decisión extintiva del contrato laboral que el empresario pueda tomar al amparo del art. 52.d de la LET pueda afectar la salud del trabajador afectado, ya que a su vez ella no puede ser adoptada en caso de enfermedades graves o de larga duración y en otros supuestos contemplados como ausencias por embarazo o violencia de género. En efecto, el Tribunal parece considerar proporcionada la medida de que las ausencias intermitentes durante un período de tiempo determinado, derivadas de enfermedades de corta duración, puedan ser consideradas para el despido objetivo. Ello así, en función del gran número de excepciones que contempla la norma, lo que se desprende de su afirmación de que "el legislador ha pretendido mantener de este modo un equilibrio entre los intereses de la empresa y la protección y seguridad de los trabajadores, evitando que con la medida prevista en el art. 52 d LET se produzcan situaciones injustas o efectos perversos" (FJ 4).

Por otro lado, y con respecto al derecho al trabajo (art. 35 CE), el Tribunal parece defender el mismo argumento de la restricción proporcionada en función de la protección de la libertad de empresa y la productividad. Así, tras reconocer que el derecho al trabajo se concreta en su vertiente individual en el derecho a la estabilidad en el empleo o a no ser despedido sin justa causa, el Tribunal afirma que la norma cuestionada no prescinde del elemento de la justa causa "sino que dota a la definición de la concreta causa extintiva del contrato de trabajo que regula- el absentismo laboral- de objetividad y certidumbre" (FJ 6). Esta restricción, asimismo, resultaría proporcionada en función de las excepciones que establece la propia norma al despido por ausencia laboral y por el establecimiento 
de la correspondiente indemnización al trabajador en caso que el empresario opte por la decisión extintiva. ${ }^{4}$

En definitiva, el Tribunal considera que las restricciones a los derechos mencionados resultan legítimas y proporcionadas en función de una correcta ponderación por parte del legislador de los intereses en conflicto. Este enfoque es duramente criticado por los votos particulares por las razones que, en forma sucinta, expondré en el siguiente apartado.

\section{Las razones de los disidentes.}

Los magistrados Valdés Dal-Re, Conde-Pumpido Tourón, Xiol Ríos y Balaguer Callejón componen la disidencia de la sentencia bajo análisis. Resulta imprescindible detenerse en el voto de Fernando Valdés Dal- Re ya que es el que estructura la disidencia, con alguna breve mención a consideraciones particulares que introduce la magistrada María Luisa Balaguer Callejón.

La crítica de Valdés Dal- Ré apunta hacia la construcción argumental de la sentencia y, principalmente, hacia la utilización del juicio de ponderación que realiza la misma. Así, el magistrado señala que la norma cuestionada vulnera con claridad el derecho al trabajo protegido por el artículo 35.1 CE porque en su regulación de la extinción del contrato laboral por absentismo, no resguarda el contenido esencial del derecho fundamental. Dicho contenido esencial, afirma el magistrado, supone principalmente la necesidad de una justa causa para el despido de cualquier trabajador y, por legítimo que sea el objetivo de combatir el absentismo, el establecimiento de un régimen de causalidad extintiva ligado a él debe respetar ese contenido esencial. (FJ 6)

Sin embargo, a juicio del magistrado, dicha ponderación falla en la sentencia bajo análisis ya que, por un lado, se introducirían elementos erróneos en la balanza de la ponderación que permitirían afirmar la existencia de un equilibro en los intereses en punga y, por el otro, la supuesta colisión de derechos entre el derecho al trabajo (art. 35 CE) y el derecho a la libertad de empresa y la productividad (art. 38 CE) no sería tal (FJ 7). Considero que esta crítica que realiza el magistrado Balaguer al voto de la mayoría es central ya que no solo se incluyen en el juicio de ponderación ciertas exclusiones que establece el art. 52.d de la LET que en nada se relacionan con las ausencias intermitentes por enfermedades de corta duración (que es la causal de despido cuestionada) sino que a su vez se le atribuye a libertad de empresa un contenido más amplio y un poder extensivo sobre otros derechos fundamentales que verdaderamente no posee.

Sobre el juicio de ponderación y el contenido esencial del derecho al trabajo centraré mi comentario de esta sentencia en el próximo apartado. Previo a ello, considero necesario destacar las consideraciones realizadas por la magistrada María Luisa Balaguer Callejón relativas a la existencia de discriminación por discapacidad y la vulneración del artículo 14 CE. La magistrada pone el foco en la largamente debatida asimilación entre discapacidad y enfermedad, señalando que en el caso concreto la trabajadora poseía una enfermedad atribuible a su discapacidad, entendida esta última como una limitación de su capacidad derivada de dolencias físicas o mentales que impiden su participación plena en la vida profesional en igualdad de condiciones con otros trabajadores, tal como la interpreta

4 Entre esas excepciones el Tribunal destaca las relacionadas con ausencias por huelga, ejercicio de actividades sindicales, accidente laboral, embarazo y lactancia, etc. 
el TJUE en el asunto "Ruiz Conejero" ${ }^{5}$. Así y en función a su vez de los lineamientos de la Directiva 2000/786, la magistrada concluye que solo en el supuesto de que pueda considerarse que la norma nacional que permite al empresario despedir a un trabajador debido a sus ausencias por enfermedad derivada de su discapacidad se limita a lo necesario para combatir el absentismo laboral podrá considerarse a la norma como proporcional y legítima.

Sin embargo, la magistrada concluye en que en las circunstancias en que se encontraba la trabajadora la extinción laboral que prevé la norma cuestionada no podía operar sin riesgo de vulnerar sus derechos fundamentales, dado que dicha causal pendía sobre ella como una amenaza que la obligaría a correr un riesgo grave para su salud con tal de conservar su empleo (FJ 3). ${ }^{7}$

\section{II. ¿Es justa la causa?: las aristas del despido por ausencia laboral.}

\section{El contenido esencial del derecho y el juicio de ponderación.}

El artículo 53 de la Constitución Española afirma que el ejercicio de los derechos reconocidos por el texto constitucional solo puede ser regulado por ley que, en todo caso, deberá respetar su contenido esencial. Es decir que, conforme al texto constitucional, cada derecho fundamental posee un contenido esencial preexistente a su desarrollo legislativo que debe ser respetado por el legislador y se configura como un límite a la actividad legisferante. Ahora bien, dicho contenido esencial es un concepto jurídico indeterminado cuyos contornos se ha encargado de definir el propio Tribunal Constitucional. Así, ya en su temprana Sentencia 11/1981, de 8 de abril, el Tribunal se encargó de definir al contenido esencial como aquella parte del contenido sin la cual el derecho pierde su peculiaridad y la cual es ineludiblemente necesaria para que el titular del derecho pueda satisfacer los intereses para cuya consecución el derecho se otorga (FJ 10). Es por ello que se señala que el Tribunal ha optado por una teoría absoluta del contenido esencial, que indica que hay en los derechos fundamentales un núcleo resistente a la acción del legislador, sea cual fuere la finalidad buscada con la limitación del derecho. (Medina Guerrero, 2008: 1168).

Con relación al derecho al trabajo y como se expuso al detallar los argumentos de la sentencia bajo análisis, uno de sus elementos esenciales en su faz individual consiste en la estabilidad en el empleo de la que goza todo trabajador, que imposibilita los despidos sin justa causa. Esto ha sido reconocido por diversos instrumentos internacionales como la Carta Europea de Derechos Fundamentales, la Carta Social Europea y el Convenio $n^{\circ} 158$ de la Organización Internacional del Trabajo8, pero también por el propio Tribunal Constitucional en tempranos pronunciamientos. En su STC 22/1981, de 2 de julio, el Tribunal sostuvo que el derecho al trabajo "en su aspecto individual se concreta en el igual derecho de todos a un determinado puesto de trabajo si se cumplen los requisitos necesarios

\footnotetext{
5 STJUE de 18 de enero de 2018, Ruiz Conejero, C 270/16, par. 28

6 Directiva 2000/78/CE del Consejo, de 27 de noviembre de 2000, relativa al establecimiento de un marco general para la igualdad de trato en el empleo y la ocupación.

7 La magistrada destaca también la existencia de una discriminación indirecta por razón del género ya que la doble jornada de trabajo (oficina y hogar) afecta mayoritariamente a las mujeres provocando un daño en su salud y una merma de sus capacidades laborales. Para mayor abundamiento véase el último fundamento jurídico del voto particular.

8 Así, por ejemplo, el Convenio $n^{\circ} 158$ de la OIT dispone en su art. 4 que: "No se pondrá término a la relación de trabajo de un trabajador a menos que exista para ello una causa justificada relacionada con su capacidad o su conducta o basada en las necesidades de funcionamiento de la empresa, establecimiento o servicio."
} 
de capacitación, y en el derecho a la continuidad o estabilidad en el empleo, es decir, a no ser despedidos si no existe una justa causa" (FJ 8). ${ }^{9}$ Ahora bien, así como el contenido esencial es un concepto jurídico indeterminado la justa causa también, y la decisión sobre si ella concurre en cada despido deberá ser analizada caso por caso en función de los lineamientos jurisprudenciales principalmente. Sin embargo, no debe perderse de vista que el propio Convenio $n^{\circ} 158$ OIT establece limitaciones al legislador a la hora de regular el despido objetivo por ausencias laborales, al prohibir que el despido se base en ciertas causas sospechosas de ser discriminatorias como las basadas en su afiliación sindical, religión, sexo o, en lo que aquí interesa más, enfermedad. ${ }^{10}$

La cuestión radica entonces, en analizar si la causa esgrimida por el legislador para habilitar el despido objetivo del trabajador consagrado en el art. 52 d de la LET - a saber, la defensa de la libertad de empresa y de la productividad - justifica la excepción a la prohibición de despido por ausencias temporales del trabajo motivadas por enfermedad o lesión que establece el propio convenio de la OIT. Llegado a este punto, no puedo más que compartir la opinión de los magistrados de la disidencia y, en particular, del magistrado Valdés Dal - Re quien da en la clave del problema del voto de la mayoría, consistente fundamentalmente en su incorrecto abordaje del conflicto constitucional. Resulta ilustrativo de ello el razonamiento expresado por el voto de la mayoría cuando indica que "el legislador puede establecer, dentro de su margen de configuración y ponderando los derechos e intereses en conflicto, limitaciones a la aplicación del párrafo 1 del art. 6 del Convenio 158 de la OIT, como efectivamente lo ha hecho mediante la regulación contenida en el art. 52 d) LET" (FJ 6) y que la limitación al derecho al trabajo se ha realizado con una finalidad legítima que "encuentra fundamento constitucional en la libertad de empresa y defensa de la productividad" (FJ 6). El problema radica justamente, en que su juicio de ponderación el Tribunal no alcanza a explicar con claridad el conflicto de intereses entre el derecho al trabajo y la defensa de la libertad de empresa y la productividad.

Para comprender mejor el problema, resulta oportuno recordar la esencia del llamado juicio de ponderación. Atienza (2010: 53-55) describe a la ponderación como un razonamiento con dos premisas: en la primera se establece que en relación con un determinado caso existen dos principios aplicables, mientras que en la segunda se establece que en relación con ese caso concreto y teniendo en cuenta sus circunstancias, prevalece un principio sobre el otro. Asimismo, destaca que la ponderación solo tiene lugar allí donde no existe una regla aplicable al caso y que lo primero que debe hacer quien pondera es preguntarse justamente si es necesario ponderar, ya que la ponderación supone un cierto grado de discrecionalidad que la hace mucho más limitada para los tribunales que para el legislador (dado el margen de discrecionalidad política con el que este cuenta).

Dicho esto, creo que en la sentencia bajo análisis el juicio de ponderación no es correcto ya que no existe verdadero conflicto de derechos entre el derecho al trabajo y la libertad de empresa y defensa de la productividad. Y ello, porque como bien señala el magistrado Valdés Dal-Re en su voto particular, la garantía de la libertad de empresa apunta principalmente al desempeño de la misma en una economía de mercado, a su libertad de iniciativa y al derecho al ejercicio de esa actividad en condiciones de igualdad, pero no a

9 Este criterio ha sido sostenido por el Tribunal en otros pronunciamientos como las SSTC 20/1994, del 27 de enero; 125/1994, del 25 de abril y 118/2014, del 16 de Julio.

10 Ver arts. 5 y 6 del Convenio ${ }^{\circ} 158$ OIT. El artículo 6 especialmente dispone que "la ausencia temporal del trabajo por motivo de enfermedad o lesión no deberá constituir una causa justificada de terminación de la relación de trabajo". 
la afectación que los derechos laborales puedan ocasionar en la producción o ganancia de la empresa. ${ }^{11}$ Esta visión parece ser apoyada por la doctrina mayoritaria al referirse al contenido esencial de este derecho. Así, por ejemplo, lo hicieron tempranamente Rubio Llorente (1996: 445) al destacar que la libertad de empresa conlleva la necesaria igualdad de todas las empresas que se dedican a una misma actividad en el mercado o Aragón Reyes (1995:33) al indicar que la libertad de empresa conlleva la libertad de iniciar la actividad, desarrollarla y abandonarla cuando se lo desee.

De este modo, entonces, el conflicto constitucional que plantea la disposición cuestionada no se relaciona con la decisión respecto a un aparente conflicto de derechos sino más bien se reduce a determinar si la causal de despido establecida por el art. $52 \mathrm{~d}$ de la LET (ausencias intermitentes por enfermedad) puede ser considerada como justa causa de despido. Para considerar la existencia o inexistencia de una justa causa en el despido, deberé referirme a la relación entre discapacidad y enfermedad y la conexión entre el derecho a la salud y el derecho al trabajo en este caso concreto.

\section{La asimilación de la enfermedad a discapacidad y su incidencia en la justa causa.}

Para determinar si la causal de despido que establece la disposición cuestionada puede ser considerada como justa causa es necesario primero atender a la innegable conexión que el derecho al trabajo guarda con el derecho a la salud en el caso bajo análisis, atento a que el derecho a la salud se encuentra en la base del régimen extintivo cuestionado. Asimismo, no cabe perder de vista la conexión existente entre el derecho a la salud y el derecho a la integridad física y moral garantizado por el artículo 15 de la Constitución Española. Dicho esto, adelanto aquí que en este punto me acerco más a la posición de la magistrada Balaguer Callejón que a la de Valdés Dal-Re, en el sentido de considerar que no solo la disposición cuestionada vulnera el derecho al trabajo, sino también el derecho a la salud y a la integridad física y moral. Ello así, porque ha sido el propio Tribunal el que ha destacado la conexión entre el derecho a la salud y a la integridad personal, si bien su doctrina resulta un poco ambigua en cuanto a los criterios que deben cumplirse para que exista dicha conexión en cada concreto. En líneas generales, sin embargo, puede afirmarse junto a Guerrera Vaquero (2015:1269-1271) que el Tribunal sostiene que el derecho a que no se dañe la salud personal queda comprendido en el derecho a la integridad personal y que para que se produzca la lesión a la integridad personal no es necesario que exista un daño efectivo a la salud sino que basta con el mero riesgo de daño o lesión de la salud. ${ }^{12}$

Por otro lado, resulta oportuno en este análisis evaluar también la incidencia del artículo 14 CE y su prohibición de discriminación. Dicho artículo contiene categorías que tradicionalmente han sido consideradas como sospechosas de discriminación (como el lugar de nacimiento, raza, sexo o religión) pero también una cláusula genérica al final que prohíbe la discriminación por "cualquier otra condición o circunstancia personal o social". Surge el interrogante entonces de si un despido por incapacidad temporal del trabajador motivada por su enfermedad puede ser considerado discriminatorio y por tanto reputarse nulo. Si se observan los tempranos pronunciamientos tanto del Tribunal Supremo como del Tribunal Constitucional, se concluye claramente que, en un primer momento,

11 Véase el Fundamento Jurídico 7 del voto particular del magistrado Valdés Dal-Re para una clara exposición de la construcción jurisprudencial de la libertad de empresa realizada por el Tribunal Constitucional.

12 La ambigüedad doctrinaria radica principalmente en la intensidad del riesgo de lesión de la salud requerida para que se configure una lesión a la integridad personal. Así, por ejemplo, mientras algunas sentencias refieren a un riesgo de daño inmediato o futuro (STC 35/1996, FJ 3), otras refieren a la necesidad de un riesgo palmario y manifiesto (STC 220/2005, FJ 3) o grave y cierto (STC 62/2007, FJ 4). 
los despidos por enfermedad no constituían factores de discriminación en la jurisprudencia española. Así, el Tribunal Supremo en su Sentencia de 29 de enero de 2001 (RJ 2001/2069) sostuvo expresamente que "la enfermedad, en el sentido genérico que aquí se tiene en cuenta desde una perspectiva estrictamente funcional de incapacidad para el trabajo, que hace que el mantenimiento del contrato de trabajo del actor no se considere rentable por la empresa, no es un factor discriminatorio en el sentido estricto que este término tiene en el inciso final del artículo 14 de la Constitución Española, aunque pudiera serlo en otras circunstancias en las que resulte apreciable el elemento de segregación" (FJ $2^{\circ}$ ). Por su parte, el Tribunal Constitucional también se expresó en este sentido en la STC 62/2008, de 26 de junio, cuando al analizar la nulidad de un despido por las bajas laborales de un trabajador derivadas de su enfermedad el Tribunal concluyó que "una decisión de despido como la aquí analizada, basada en la pretendida incapacidad del trabajador para desarrollar su trabajo por razón de su enfermedad o de su estado de salud, podrá conceptuarse legalmente como procedente o improcedente, en virtud de que se acredite o no la realidad de la causa alegada y de que ésta sea o no efectivamente incapacitante, pero no constituye en sí misma una decisión discriminatoria." (FJ 6º). En definitiva, estos pronunciamientos se adscriben a la línea tradicional que indica que la causa del despido no es la enfermedad del trabajador sino su incapacidad derivada de la misma, lo que merma la productividad empresarial y por tanto configura una justa causa de despido al perseguir la finalidad legítima de combatir el absentismo laboral.

Ahora bien, lo cierto es que esta doctrina reconoce un viraje propulsado en gran medida por la jurisprudencia del TJUE y la normativa europea, que puso el foco en el hecho de que, en determinadas circunstancias, la enfermedad del trabajador puede asimilarse a una verdadera discapacidad y, por lo tanto, el despido en estos supuestos sería nulo por discriminatorio.

Este cambio fue provocado, en primer lugar, por el dictado de la Directiva 2000/78 que en su artículo 2 prohíbe expresamente la discriminación por discapacidad del trabajador y obliga al empresario a adoptar medidas para eliminar las disposiciones, prácticas o criterios discriminatorios imperantes en su organización. El problema es que esta directiva no otorga una definición de discapacidad ni aclara cuando un despido puede ser considerado nulo por discriminatorio. Sin embargo, el ordenamiento español sí consagra una definición de discapacidad en la Ley general de derechos de las personas con discapacidad y de su inclusión social al definir en su artículo 1 a las personas con discapacidad como aquellas “que presentan deficiencias físicas, mentales, intelectuales o sensoriales, previsiblemente permanentes que, al interactuar con diversas barreras, puedan impedir su participación plena y efectiva en la sociedad, en igualdad de condiciones con los demás". Esto ha llevado a la doctrina a preguntarse si el despido por la incapacidad temporal derivada de la enfermedad no supone entonces un supuesto de discriminación por discapacidad, ya que en este caso devendría nulo en función de la prohibición dispuesta por la Ley del Estatuto de los Trabajadores. ${ }^{13}$

No es objeto del presente comentario una disquisición harto extensa sobre la relación entre discapacidad y enfermedad. Sin embargo, considero necesario destacar como la consolidación de la asimilación de enfermedad a discapacidad en determinados supuestos en la jurisprudencia española y europea resulta determinante para excluir tajante-

$13 \mathrm{El}$ art. 4.2.c de la Ley del Estatuto de los Trabajadores dispone que en la relación de trabajo los trabajadores no podrán ser discriminados, entre otros motivos, "por razón de discapacidad, siempre que se hallasen en condiciones de aptitud para desempeñar el trabajo o empleo de que se trate". 
mente la existencia de una justa causa en la causal de despido configurada por el (hoy derogado) artículo 52.d de la LET. Así, en un primer momento el Tribunal Supremo en su Sentencia de 22 de enero de 2008 (RJ 2008\1621) rechazó esta asimilación al considerar que la enfermedad era una mera alteración de la salud contingente, mientras que la discapacidad suponía una situación permanente de minusvalía que alteraba de manera permanente las condiciones de vida de la persona discapacitada y, además, requería de una declaración oficial para ser reconocida como tal (FJ $5^{\circ}$ ). Y la misma línea siguió el TJUE en el asunto "Chacón Navas" cuando sostuvo que el despido de un trabajador basado exclusivamente en su enfermedad no estaba incluido en el ámbito de protección del Tratado de la Comunidad Europea y tampoco cabía deducirlo por analogía del ámbito de aplicación de la Directiva 2000/78. ${ }^{14}$

Sin embargo, a nivel europeo el TJUE ha impulsado un cambio de esta teoría, tendiendo a asimilar cada vez más a la enfermedad con la discapacidad y exigiendo que todos los operadores jurídicos tengan en cuenta esta condición de los trabajadores para evitar discriminaciones prohibidas. En el asunto "HK Danmark" el TJUE sostuvo que el concepto de discapacidad "comprende una condición causada por una enfermedad diagnosticada médicamente como curable o incurable, cuando esta enfermedad acarrea una limitación, derivada en particular de dolencias físicas, mentales o psíquicas que, al interactuar con diversas barreras, puede impedir la participación plena y efectiva de la persona de que se trate en la vida profesional en igualdad de condiciones con los demás trabajadores, si esta limitación es de larga duración" ${ }^{15}$ Conforme a esta doctrina, entonces, el concepto de discapacidad engloba al de enfermedad de larga duración que comporte limitaciones en la vida profesional, al punto tal que se ha llegado a afirmar que el Tribunal ha creado la figura de enfermedad asimilable a discapacidad que afecta a trabajadores que sufren enfermedades que le generan faltas de asistencia al trabajo sin que éstas lleguen a alcanzar un carácter definitivamente invalidante. (Velasco Portero, 2014:11). Posteriormente, el TJUE avanza en la asimilación de las enfermedades de corta duración a discapacidad en el asunto "Ruiz Conejero", donde a raíz de un despido basado en el artículo 52.d de la LET el Tribunal afirma que la Directiva $2000 / 78$ se opone a una normativa nacional que permita al empresario despedir a un trabajador debido a las faltas de asistencia de éste al trabajo, aún justificadas pero intermitentes, cuando tales ausencias sean consecuencia de enfermedades atribuibles a la discapacidad de este trabajador, salvo que dicha normativa tenga la finalidad legítima de combatir el absentismo y no vaya más allá de lo necesario para alcanzar esa finalidad. Este juicio de proporcionalidad a su vez, quedará a cargo del órgano jurisdiccional de cada caso concreto que, en todo caso, deberá tener especialmente en cuenta el riesgo que corren las personas afectadas por una discapacidad, que en general encuentran más dificultades que los trabajadores sin discapacidad para reincorporarse al mercado de trabajo y tienen necesidades específicas ligadas a la protección que requiere su estado. ${ }^{16}$

De lo expuesto puede observarse como la jurisprudencia europea considera posible la asimilación a discapacidad de las enfermedades temporales que generen ausencias intermitentes del trabajador, lo que calificaría al despido basado en esta causa como nulo. Si bien como afirma Barreira Igual (2018:216) la doctrina del TJUE no es concluyente, ya que deja librado a la interpretación de los órganos jurisdiccionales nacionales el juicio

14 STJUE de 11 de julio de 2006, Chacón Navas, C-13/05, ap., 54-57. 15 STJUE de 11 de abril de 2013, HK Danmark, C 335/11 y C 337/11, ap., 47. 16 STJUE de 18 de enero de 2018, Ruiz Conejero, C 270/16, ap. 51-57. 
sobre la proporcionalidad de la medida de despido adoptada, lo cierto es que la doctrina aporta a mi juicio lineamientos claros en el sentido de que cualquier enfermedad que impida el desenvolvimiento pleno de la actividad profesional del trabajador en condiciones de igualdad puede ser considerada como discapacidad y, por ende, un despido que tenga como causa las ausencias derivadas de la misma debe ser reputado nulo.

Es por ello que, en estos supuestos, resulta difícil de aceptar la argumentación que emplea el voto de la mayoría del Tribunal Constitucional en la sentencia bajo análisis relativo a que la causal de despido que habilita el art. 52. d de la LET no genera un daño o riesgo de daño a la salud del trabajador ya que "se limita a autorizar el despido para el caso de que se supere un número de faltas de asistencia al trabajo intermitentes, justificadas o no, en un determinado período de tiempo". (FJ 3). Por el contrario, la normativa europea y la interpretación que de la misma ha hecho el Tribunal de Justicia de la Unión Europea parece ir en la dirección contraria, asimilando también estos supuestos de enfermedades de corta duración a la discapacidad.

Por lo expuesto, considero que sería altamente beneficioso que la doctrina del Tribunal Constitucional y otros órganos judiciales españoles se pliegue rápidamente a la desarrollada por el TJUE en el materia, no tanto porque en este diálogo de tribunales uno sea realmente superior al otro, sino porque considero que en este caso particular la declaración del despido como nulo por discriminación era la solución justa. El enfoque adoptado por los magistrados disidentes da esperanzas de ello.

\section{Conclusiones}

La STC 118/2019, de 16 de Octubre de 2019, constituye un objeto de estudio atrapante para todo jurista ya que permite observar la incidencia que tiene en la justicia constitucional tanto la utilización de ciertos esquemas argumentales tradicionales pero poco precisos como el juicio de ponderación y el juicio de proporcionalidad, así como de conceptos jurídicos indeterminados como el de contenido esencial del derecho o el de justa causa. El planteamiento de un conflicto constitucional entre el derecho al trabajo y la libertad de empresa conduce al Tribunal Constitucional a concluir en la existencia de una restricción legítima al derecho del trabajador en aras de garantizar la defensa de la productividad empresarial. Como se expuso, esta conclusión no solo resulta débil porque toma como medida de la proporcionalidad de la restricción la existencia de una indemnización por despido y la exclusión que hace la ley de otras ausencias por enfermedad como causal de despido, sino también porque se enfoca en un conflicto de derechos inexistente.

El Tribunal Constitucional, con esta sentencia, consolida su reiterada doctrina en la materia, desconociendo el vínculo entre enfermedades de corta duración y discapacidad, y dejando vía libre para el despido con justa causa de trabajadores cuyas ausencias temporales e intermitentes se deban a este tipo de enfermedades. Esta doctrina, tal como también lo expresan los magistrados disidentes, no parece acompañar la tendencia normativa y jurisprudencial europea que tiende a asimilar cada vez estas enfermedades a discapacidad y considerar nulos a los despidos motivados en ellas. Asimismo, y si bien el Tribunal reconoce y se refiere expresamente a esta jurisprudencia europea, lo cierto es que la interpretación que realiza de la misma resulta cuestionable, ya que, si bien el TJUE ha reconocido que corresponde a los órganos jurisdiccionales nacionales determinar en cada concreto si las restricciones a los derechos del trabajador resultan proporcionales para alcanzar la finalidad legítima de combatir el absentismo laboral, lo cierto es que de 
una lectura global de la misma emergen claros límites constitucionales que la disposición cuestionada del art. 52.d de la LET no parece respetar.

Cabe destacar que recientemente, y compartiendo muchas de las consideraciones expuestas en este comentario, el Real Decreto-ley 4/2020, de 18 de febrero, ha derogado el artículo 52.d) del texto refundido de la Ley del Estatuto de los Trabajadores. Resta esperar, entonces, que el Tribunal Constitucional modifique su doctrina en futuros pronunciamientos y, siguiendo la corriente europea, otorgue una mayor protección a los trabajadores que se ven obligados a ausentarse de su trabajo por enfermedades de corta duración.

\section{REFERENCIAS BIBLIOGRÁFICAS}

- Atienza, M. (2010). A vueltas con la ponderación. Anales de la cátedra Francisco Suárez, 44, 43-59.

- Aragón Reyes, M. (1996). Constitución económica y libertad de empresa. En J.L Iglesias Prada (Coord.), Estudios jurídicos en homenaje al profesor Aurelio Menéndez, Vol. 1. (pp. 163-180). España: Civitas

- Barreira Igual, M. (2018). Discapacidad y enfermedad en el despido. Aplicación práctica. Revista Internacional y Comparada de Relaciones Laborales Y Derecho del Empleo. (6, 4), 197-217.

- Guerrera Vaquero, A. (2015). La protección de la salud y del derecho a la integridad física en tiempos de crisis. Revista de Derecho UNED, (16), 1265-1292. Disponible en https:// doi.org/10.5944/rduned.16.2015.15277

- Medina Guerrero, M. (2008). Comentario a los artículos 53. 1 y 2 y 142 CE. En M.E. Casas Baamonde y M. Rodriguez-Piñero (Eds.), Comentarios a la Constitución Española. XXX aniversario (pp. 1158-2158). Madrid: Fundación Wolters Kluwer.

- Rubio Llorente, F. (1996). La libertad de empresa en la Constitución. En J.L Iglesias Prada (Coord.), Estudios jurídicos en homenaje al profesor Aurelio Menéndez, Vol. 1. (pp. 431-446). España: Civitas.

- Velasco Portero, T. (2014). "El despido del trabajador enfermo: ¿Improcedencia o nulidad?". Revista General del Derecho del Trabajo y de la Seguridad Social, (39), 11-40. 